\title{
Evaluación de la calidad del agua de los arrecifes del golfo de Cazones, sur de Cuba, a partir de algunos indicadores microbiológicos y químicos
}

\section{Water quality assessment of reefs in the gulf of Cazones, southern Cuba, using microbiological and chemical indicators}

\author{
Gladys Margarita Lugioyo ${ }^{1 *}$ Daymarlen González e Ileana García $^{1}$
}

\begin{abstract}
RESUMEN
Los arrecifes coralinos constituyen uno de los ecosistemas más amenazados por los efectos de la actividad antrópica y el cambio climático, impactos a los cuales no escapan los arrecifes del Mar Caribe. El objetivo de la investigación fue la evaluación de la calidad del agua aledaña a los arrecifes del golfo de Cazones, $\mathrm{S}$ de $\mathrm{Cuba}$, a partir de algunos indicadores microbiológicos y químicos. Se realizaron dos muestreos en épocas contrastantes, noviembre 2015 (invierno) y abril 2017 (verano), donde se tomaron 13 muestras de agua (cinco en las crestas y ocho en los arrecifes frontales). Los arrecifes más vulnerables, tomando en consideración los indicadores seleccionados microbiológicos y químicos de calidad de las aguas, fueron Sureste de cayo Diego Pérez 2 (SE-Cy.DP2), Sureste de cayo Diego Pérez 1 (SE-Cy.DP1) y Sur de la ensenada de Cazones (S-EC) (Nirvana), al presentar elevadas concentraciones de bacterias heterótrofas, de sulfato-reductoras, de vibrios y de materia orgánica (DQO). De acuerdo con la concentración de bacterias heterótrofas, el estado trófico de las aguas varió entre mesotróficas a meso-eutróficas y el sitio más deteriorado fue el oeste de la ensenada de Cazones (O-EC), seguido de este de la ensenada de Cazones (E-EC) y sur de la ensenada de Cazones (S-EC) lo que indica que las aguas aledañas a esos arrecifes se mantienen enriquecidas de materia orgánica, tanto en las crestas como en los arrecifes frontales. Los resultados obtenidos deben servir de alerta, ya que existen condiciones para el deterioro paulatino de los arrecifes.
\end{abstract}

Palabras clave: Calidad, bacterias, hidroquímica, arrecifes, ecosistema.

\section{ABSTRACT}

Coral reefs are some of the most threatened ecosystems due to the anthropogenic activity and climate change, from which the Caribbean Sea reefs have not escaped. The objective of this paper was to assess the quality of the waters adjacent to the reefs of the Gulf of Cazones, southern

1 Instituto de Ciencias del Mar (ICIMAR), calle Loma \# 14, entre 35 y 37, Plaza de la Revolución, La Habana, Cuba. margarita@icimar.cu* ORCID: https://orcid.org/0000-0001-7517-8063, mimi@icimar.cu ORCID: https://orcid.org/0000-0002-4653-1347, ileana@icimar.cu ORCID: https://orcid.org/0000-0003-2229-3767. 
Cuba, using certain microbiological and chemical indicators. Two samplings were conducted in contrasting seasons, November 2015 (winter) and April 2017 (summer), where 13 water samples were taken (five on the ridges and eight on the front reefs). The most vulnerable reefs to environmental deterioration in both seasons, taking into consideration the microbiological and chemical indicators, were Southeast of Cayo Diego Pérez 2 (SE-Cy.DP2), Southeast of Cayo Diego Pérez 1 (SE-Cy.DP1), and South of Cazones Cove (S-EC) (Nirvana), since they had high concentrations of heterotrophic and sulphate-reducing bacteria, vibrio, and organic matter (COD). Based on the heterotrophic bacteria concentration, the trophic state of the waters ranged from mesotrophic to meso-eutrophic and the most deteriorated site resides at the West of the Cazones cove (O-EC), followed by the East of the Cazones cove (E- EC) and South of the Cazones cove (S-EC). This indicates that the waters surrounding these reefs are enriched with organic matter, both on the ridges and on the frontal reefs. The results obtained should serve as a warning because conditions exist for the gradual deterioration of these coral reefs.

Keywords: Quality, bacteria, hydrochemicals, reef, ecosystem.

\section{INTRODUCCIÓN}

Los arrecifes coralinos son invaluables por su importancia ecológica, social y económica. Especialmente relevantes son los servicios ecosistémicos que bridan: fuentes de recursos alimenticios, amortiguadores de la erosión costera, barreras naturales para la protección contra fenómenos meteorológicos extremos, turismo (Spalding et al. 2017; Thampi et al. 2018). Sin embargo, en los últimos años se ha reconocido que los arrecifes coralinos constituyen uno de los ecosistemas más amenazados por los efectos de la actividad antrópica y el cambio climático (Harvey et al. 2018; Williams et al. 2019).

Alcolado et al. (2010) refieren que investigaciones de la última década sobre la salud de los arrecifes del Caribe (Aronson \& Pretch,
2001; Gardner et al. 2003) indican un deterioro de este ecosistema y lo atribuyen a los efectos de presiones locales y regionales entre los que se encuentran la contaminación y la sobrepesca (Ginsburg \& Glynn, 1994; Hoegh-Guldberg et al. 2007; Jackson et al. 2014), el incremento de la temperatura (Eakin et al. 2010; Hughes et al. 2010), la acidificación de los océanos (Kleypas \& Hoegh-Guldberg, 2008; Hughes et al. 2018; Pandolfi et al. 2005), además de las consecuencias propias del cambio climático (Weijerman et al. 2018).

Las investigaciones realizadas sobre la calidad ambiental y estado de "salud" de los ecosistemas arrecifales en Cuba demostraron que algunos arrecifes se encontraban afectados debido a varios fenómenos, entre los que se destacan la nutrificación, la incidencia de enfermedades, así como la 
acción nociva de las altas temperaturas (Miravet, 2003; Alcolado et al. 2010).

En los ecosistemas marinos, las bacterias heterótrofas constituyen un componente esencial en la trama trófica; estas, a través de su interacción con otros niveles, modifican los ambientes y controlan el reciclaje de nutrientes (Pucci et al. 2009). Teniendo en cuenta el rol ecológico de las bacterias heterótrofas en el medio marino, actualmente es reconocida la posibilidad de utilizarlas como indicadoras microbiológicas para evaluar la calidad ambiental de los ecosistemas y la detección de condiciones ambientales desfavorables.

Los vibrios es otro grupo bacteriano que puede ser usado como indicador de calidad de las aguas, ya que su distribución está influenciada por gradientes medioambientales como temperatura, salinidad, disponibilidad de nutrientes y factores biológicos, por ejemplo, depredación y abundancia de dinoflagelados y hospedadores (Thompson \& Polz, 2006). Al respecto, diversos estudios estuarinos y costeros de diferentes partes del mundo han demostrado que la temperatura y salinidad juegan funciones importantes en el desarrollo del $V$. cholerae (Jiang, 2001).

Las bacterias sulfatoreductoras, si bien son microbiota normal en ambientes con niveles bajos de oxígeno disuelto o anóxicos, como pueden ser los sedimentos marinos, cuando son detectadas en ecosistemas como los arrecifes coralinos, son indicadoras de deterioro de la salud.

En Cuba, desde el punto de vista microbiológico, solo se habían realizado investigaciones de calidad de las aguas en los arrecifes del sur oeste (SW) (Miravet, 2003) y en el archipiélago Sabana-Camagüey, ubicado en la zona norcentral de Cuba (Miravet et al. 1994). Sin embargo, en la zona en estudio no existían antecedentes de investigaciones microbiológicas y dada la importancia que reviste la calidad del agua para la conservación de los arrecifes, el objetivo del presente trabajo fue evaluar la calidad de las aguas aledañas a los arrecifes coralinos del golfo de Cazones empleando algunos indicadores microbiológicos y químicos de respuesta rápida.

\section{MATERIALES Y MÉTODOS}

La zona de trabajo se ubica en el golfo de Cazones que se encuentra dentro de las áreas marinas protegidas de la Ciénaga de Zapata. Los arrecifes del golfo de Cazones se caracterizan por crestas y arrecifes frontales pequeños y con aislados cabezos de coral sobre un sustrato de arena entre 3 $\mathrm{m}$ y $10 \mathrm{~m}$ de profundidad. A partir de los $10 \mathrm{~m}$ de profundidad se desarrolla un fondo de camellones y canales de arena, los cuales, con el aumento de la profundidad, incrementan en relieve (Rey-Villiers, 2016). 
Se realizaron dos muestreos en del 2017 (verano), donde se tomaron 13 épocas contrastantes, uno en noviem- muestras de agua (cinco en las crestas y bre del 2015 (invierno) y otro en abril ocho en los arrecifes frontales) (Fig. 1).

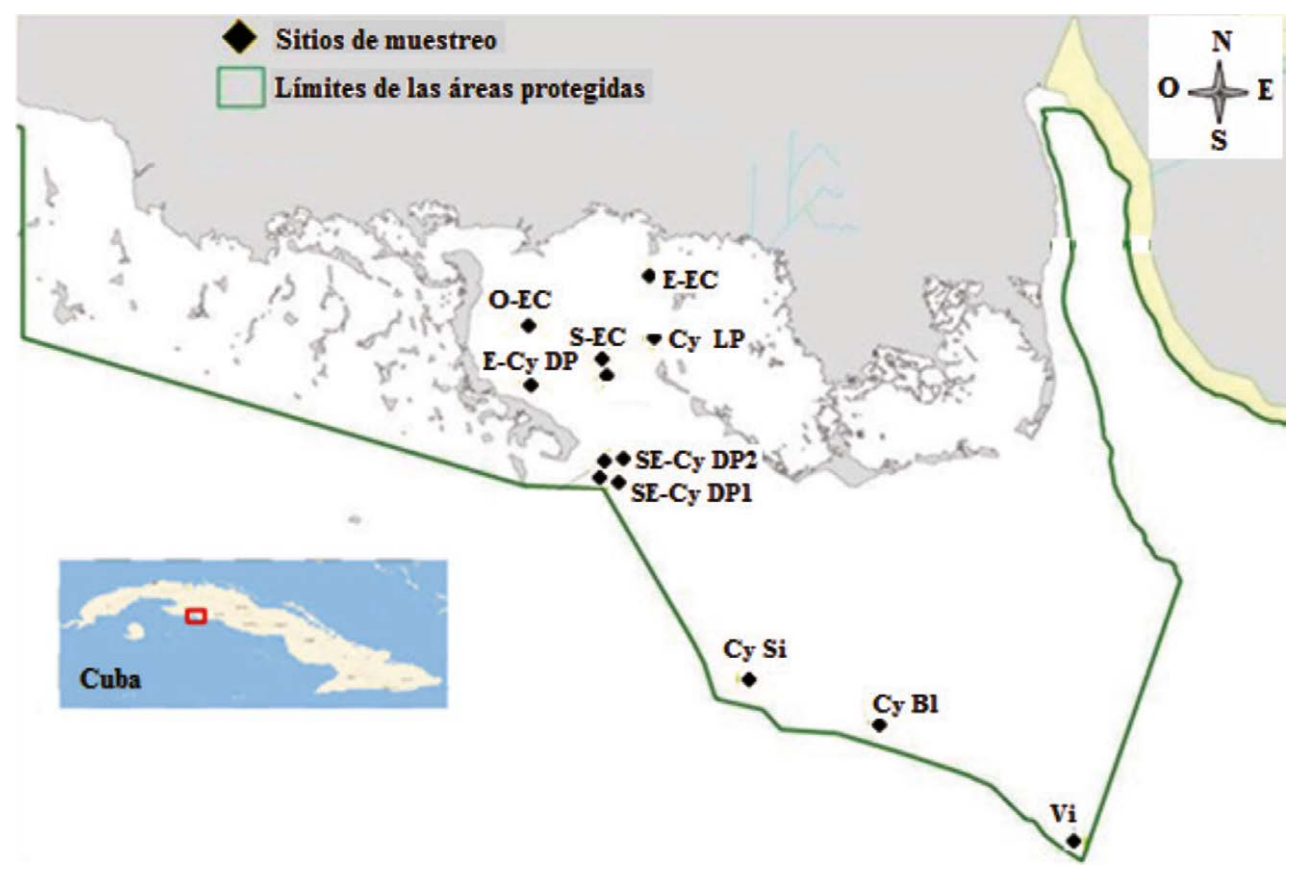

Crestas arrecifales del golfo de Cazones

\begin{tabular}{|c|c|c|c|}
\hline Sitios & Siglas & Latitud N & Longitud $\mathrm{O}$ \\
\hline Sur de la ensenada de Cazones & $S$-EC & $22^{\circ} 5.931{ }^{\prime}$ & $81^{\circ} 31.160^{\prime}$ \\
\hline Sureste de cayo Diego Pérez 2 & SE-Cy.DP2 & $22^{\circ} 2.163^{\prime}$ & $81^{\circ} 30.876^{\prime}$ \\
\hline Sureste de cayo Diego Pérez 1 & $S E$-Cy.DP1 & $22^{\circ} 1.297^{\prime}$ & $81^{\circ} 30.952^{\prime}$ \\
\hline Cayo Sigua & Cy.Si & $21^{\circ} 53.460^{\prime}$ & $81^{\circ} 25.051^{\prime}$ \\
\hline Vizcaínos & $\mathrm{Vi}$ & $21^{\circ} 47.094^{\prime}$ & $81^{\circ} 10.859^{\prime}$ \\
\hline \multicolumn{4}{|c|}{ Arrecifes frontales del golfo de Cazones } \\
\hline Este de la ensenada de Cazones & $E-E C$ & $22^{\circ} 09.400^{\prime}$ & $81^{\circ} 29.098^{\prime}$ \\
\hline Cayo Los Pinos & Cy.LP & $22^{\circ} 06.898^{\prime}$ & $81^{\circ} 29.027^{\prime}$ \\
\hline Oeste de la ensenada de Cazones & $O$-EC & $22^{\circ} 07.431$, & $81^{\circ} 34.286^{\prime}$ \\
\hline Sur de la ensenada de Cazones & $S$-EC & $22^{\circ} 05.753^{\prime}$ & $81^{\circ} 31.055^{\prime}$ \\
\hline Este de cayo Diego Pérez & E-Cy.DP & $22^{\circ} 05.099^{\prime}$ & $81^{\circ} 34.397^{\prime}$ \\
\hline Sureste de cayo Diego Pérez 2 & SE-Cy.DP2 & $22^{\circ} 02.164^{\prime}$ & $81^{\circ} 30.517^{\prime}$ \\
\hline Sureste de cayo Diego Pérez 1 & SE-Cy.DP1 & $22^{\circ} 01.253^{\prime}$ & $81^{\circ} 30.621^{\prime}$ \\
\hline Cayo Blanco & Cy.Bl & $21^{\circ} 51.748^{\prime}$ & $81^{\circ} 19.454^{\prime}$ \\
\hline
\end{tabular}

Fig. 1. Ubicación geográfica de los sitios de muestreo en el golfo de Cazones

Fig. 1. Location of sampling stations in the Gulf of Cazones 
Para el análisis microbiológico se colectaron muestras de agua aledaña a las crestas arrecifales y a los arrecifes frontales, mediante buceo autónomo y con el empleo de frascos de vidrio estériles de $250 \mathrm{~mL}$ de capacidad. Las muestras fueron conservadas en refrigeración por no más de $4 \mathrm{~h}$ hasta el procesamiento en el laboratorio de la embarcación.

La concentración de bacterias heterótrofas $(\mathrm{BH})$, como indicadora de materia orgánica en agua, se determinó a partir de la siembra por diseminación en placas Petri con el empleo del medio de cultivo ZoBell 2216E (APHA, 2012) y el medio Agar TCBS para los conteos de vibrios. Las placas fueron incubadas a temperatura $(28 \pm$ $2{ }^{\circ} \mathrm{C}$ ) y se realizaron los conteos de las unidades formadoras de colonias durante tres días consecutivos (Miravet et al. 2009).

La determinación de bacterias sulfatoreductoras, indicadoras de condiciones anóxicas, solo se realizó en el agua de los micronichos de las crestas, para ello se empleó medio API y se siguió la metodología de tubos múltiples (Miravet et al. 2009). Las muestras fueron incubadas a $28 \pm 2{ }^{\circ} \mathrm{C}$, durante 21 días. Para el cálculo de la concentración de estas bacterias se usó la Tabla de NMP (APHA, 2012).

El estado trófico de las aguas se determinó a partir de los rangos de concentración de bacterias heterótrofas propuestos por Miravet et al. (2009).
Las muestras para la determinación de materia orgánica fueron almacenadas en frascos de $1 \mathrm{~L}$ a $-10^{\circ} \mathrm{C}$ y procesadas posteriormente en el laboratorio. Se estimó la demanda química de oxígeno (DQO) por oxidación de la materia orgánica con permanganato de potasio en medio alcalino (APHA, 2012).

Para determinar si existían diferencias entre las concentraciones de bacterias heterótrofas y de vibrios entre las crestas y los arrecifes frontales de una misma zona, se empleó el análisis permutacional de varianza (PERMANOVA) (Anderson \& Millar, 2004; Anderson et al. 2008). Los factores que se tuvieron en consideración fueron las crestas y de arrecifes frontales.

\section{RESULTADOS}

Las concentraciones de bacterias heterótrofas $(\mathrm{BH})$ en el golfo de Cazones en noviembre del 2015 (época de invierno), oscilaron entre $1.1 \times 10^{3}$ y $20.4 \times 10^{3} \mathrm{UFC} \cdot \mathrm{mL}^{-1}$ (Fig. $2 \mathrm{~A}$ y B). La concentración de bacterias heterótrofas más baja en cresta se registró en la estación Vizcaínos (Vi), mientras en el sur de la ensenada de Cazones se encontró el valor más elevado de 7.2 $\mathrm{x} 10^{3} \mathrm{UFC} / \mathrm{mL}$ (Fig. 2A). En los arrecifes frontales las concentraciones más bajas de bacterias heterótrofas se obtuvieron en el sitio de Cayo Los Pinos (Cy.LP) y en sureste de cayo Diego Pérez 2 (SE-Cy.DP2); los valores más elevados de $\mathrm{BH}$ se encontraron en el 
este de cayo Diego Pérez (E-Cy.DP) y sitios E-Cy.DP y O-EC se mostraron al oeste de la ensenada de Cazones (O- elevadas concentraciones de materia EC) con concentraciones de $20.4 \times 10^{3}$ orgánica con valores de DQO de 5.48 y $10.1 \times 10^{3} \mathrm{UFC} / \mathrm{mL}$, respectivamen- y $6.72 \mathrm{mg} / \mathrm{L}$, respectivamente. te (Fig. 2A). Coincidentemente, en los
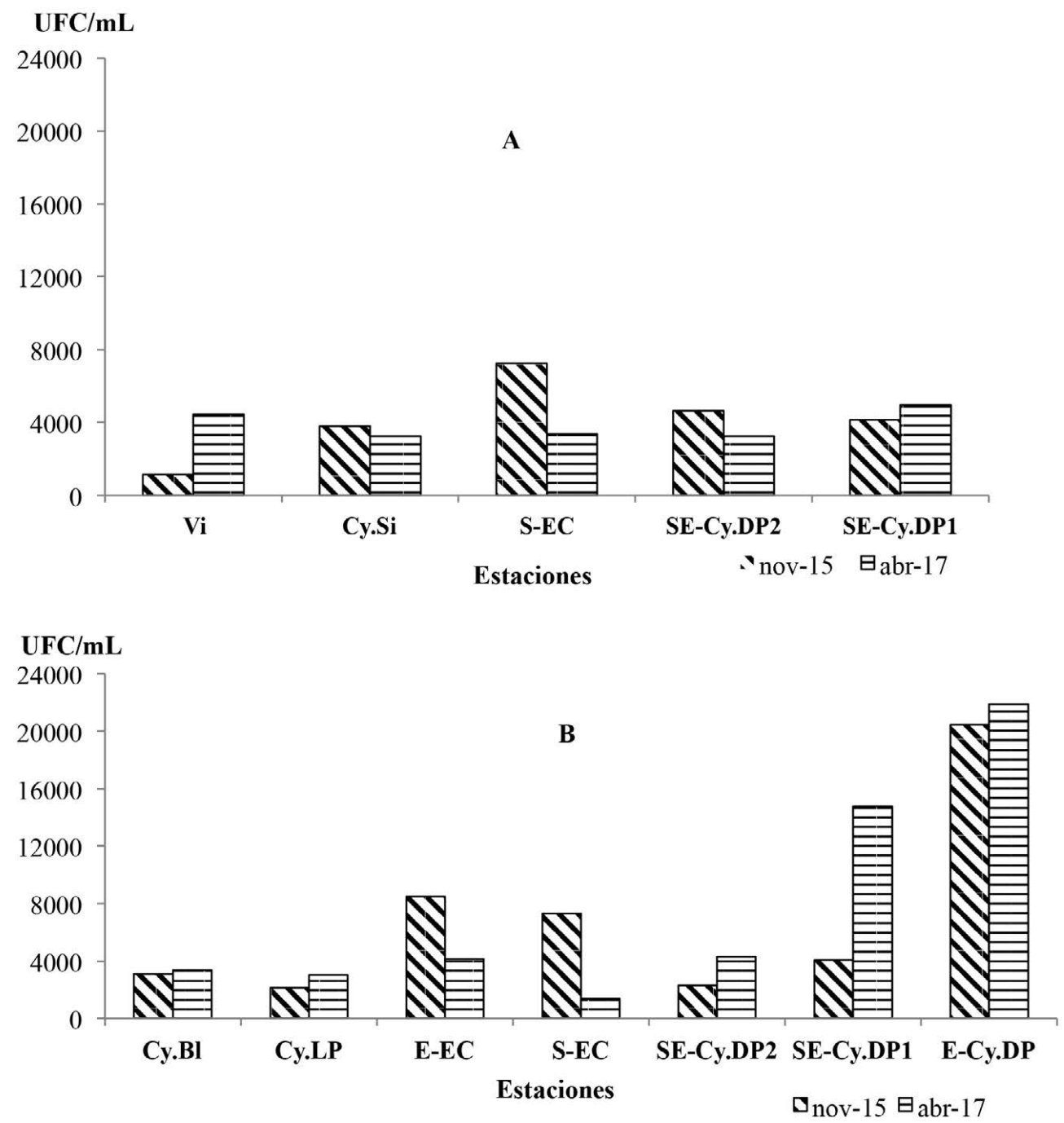

Fig. 2. Concentración de las bacterias heterótrofas $(\mathrm{BH})$ en los sitios ubicados en las crestas arrecifales (A) y los arrecifes frontales (B) en el golfo de Cazones

Fig. 2. Heterotrophic bacteria concentration $(\mathrm{BH})$ of the sites located on the reef crests (A) and the frontal reefs (B) in the Gulf of Cazones 
Por su parte, las concentraciones de $\mathrm{BH}$ en abril del 2017 oscilaron entre $1.3 \times 10^{2}$ y $14.7 \times 10^{3} \mathrm{UFC} / \mathrm{mL}$ (Fig. $2 \mathrm{~A}$ y B). La concentración de bacterias heterótrofas, en general, fue más baja en cresta en relación con los arrecifes frontales. La mayor concentración se verificó en el sitio ubicado al este de cayo Diego Pérez (E-Cy.DP), seguida del sureste de cayo Diego Pérez 1 (SE-Cy.DP1) ambos localizados en el arrecife frontal (Fig. 2B). Los menores valores de $\mathrm{BH}$ se encontraron en el sur de la ensenada de Cazones (S-EC) en el arrecife frontal.

En general, en ambos muestreos se observó que en los arrecifes frontales las concentraciones de $\mathrm{BH}$ fueron superiores respecto a las crestas arrecifales (Fig. 2A y B).
En invierno (noviembre 2015), las concentraciones de vibrio en los arrecifes, incluyendo las crestas y los arrecifes frontales, oscilaron entre 10 y $7000 \mathrm{UFC} / \mathrm{mL}$. En las crestas las mayores concentraciones de vibrio se encontraron en las estaciones sur de la ensenada de Cazones (S-EC) (7 $000 \mathrm{UFC} / \mathrm{mL}$ ) y SE-Cy.DP2 (sureste de cayo Diego Pérez 2) (1 250 UFC/ $\mathrm{mL})$, mientras en los arrecifes frontales en las estaciones sur de la ensenada de Cazones (S-EC) (1 $585 \mathrm{UFC} / \mathrm{mL}$ ) y sureste de cayo Diego Pérez 2 (SE-Cy. DP2) (1 $550 \mathrm{UFC} / \mathrm{mL}$ ). Por su parte, en abril 2017 (época de verano), las concentraciones de vibrio variaron entre 40,6 y $1912 \mathrm{UFC} / \mathrm{mL}$ y resultaron, en general, inferiores a las obtenidas en noviembre del 2015 (Cuadro 1).

Cuadro 1. Concentración de vibrios en los sitios de los arrecifes del golfo de Cazones en noviembre 2015 y abril 2017

Table 1. Vibrio concentration in the Gulf of Cazones reefs in November 2015 and April 2017

\begin{tabular}{lcc}
\hline \multicolumn{1}{c}{ Ubicación de los sitios } & \multicolumn{2}{c}{$\begin{array}{c}\text { Concentración de vibrios (UFC/ mL) } \\
\text { Noviembre 2015 }\end{array}$} \\
$\begin{array}{lcc}\text { Abril 2017 } \\
\text { Crestas arrecifales }\end{array}$ \\
\hline Vizcaínos (Vi) & 197 & 59 \\
Cayo Sigua (Cy.Si) & 10 & 41 \\
Sur de la ensenada de Cazones (S-EC) & 7000 & 1912 \\
Sureste de cayo Diego Pérez 2 (SE-Cy.DP2) & 1250 & 263 \\
Sureste de cayo Diego Pérez 1 (SE-Cy.DP1) & 77 & 267 \\
& \multicolumn{2}{c}{ Arrecifes frontales } \\
Cayo Blanco (Cy.Bl) & 852 & 312 \\
Cayo Los Pinos (Cy.LP) & 10 & 270 \\
Este de la ensenada de Cazones (E-EC) & 20 & 173 \\
Sur de la ensenada de Cazones (S-EC) & 1585 & 221 \\
Sureste de cayo Diego Pérez 2 (SE-Cy.DP2) & 1550 & 700 \\
Sureste de cayo Diego Pérez 1 (SE-Cy.DP1) & 355 & 151 \\
Oeste de la ensenada de Cazones (O-EC) & 25 & 118 \\
Este de cayo Diego Pérez (E-Cy.DP) & 415 & 312 \\
\hline
\end{tabular}


Es de destacar que, tanto en estaciones de crestas y arrecifes froncresta como en arrecifes frontales, la tales del golfo de Cazones. mayor concentración de vibrios se encontró en el sitio ubicado al sur de la ensenada de Cazones (S-EC) en ambos muestreos (Cuadro 1).

Al realizar el análisis de PERMANOVA no se hallaron diferencias significativas de la concentración de BH (Pseudo-F de 1.1201 y P (perm) 0.34) y de vibrios (Pseudo-F de 1.0571 y $\mathrm{P}$ (perm) 0,398) ni entre las
En las crestas, el análisis de la contribución relativa de los vibrios a la concentración total de bacterias heterótrofas evidenció que, en general, en ambos muestreos el porcentaje de vibrios fue bajo en todos los sitios, con excepción de la estación ubicada al sur de la ensenada de Cazones (S-EC) que en noviembre 2015 fue de $96.8 \%$ y de 56.7\% en abril 2017 (Fig. 3A y B).
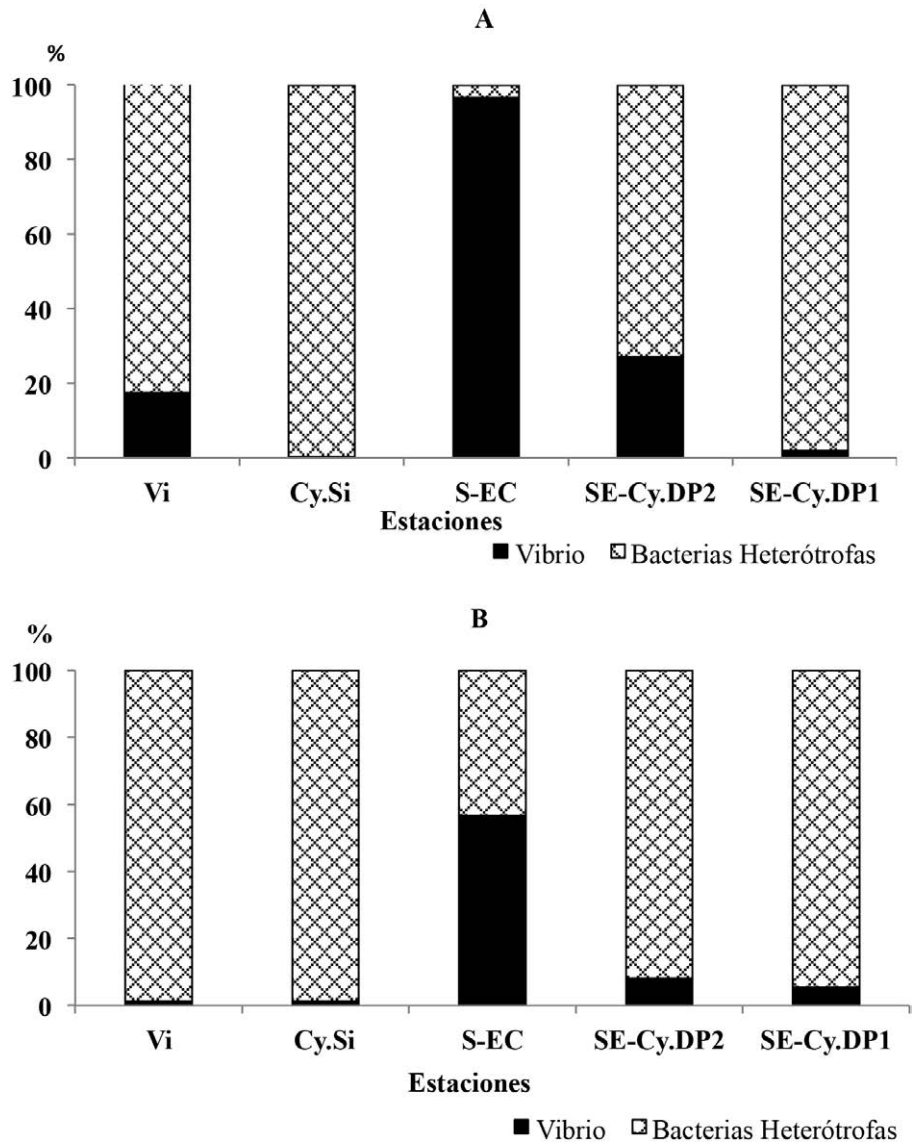

Fig. 3. Contribución relativa de la concentración de vibrios al total de bacterias heterótrofas en las crestas arrecifales del golfo de Cazones. A: noviembre 2015, B: abril 2017

Fig. 3. Relative contribution of vibrio to the total heterotrophic bacteria concentration on the reef crest in the Gulf of Cazones. A: November 2015, B: April 2017 
En relación con la contribución la ensenada de Cazones (S-EC) con de los vibrios en los arrecifes fronta- una contribución de $21.7 \%$ (Fig. 4A). les, en noviembre del 2015 se destacan En abril del 2017 las estaciones que los sitios sureste de cayo Diego Pérez más contribuyeron los vibrios al total 2 (SE-Cy.DP2) con $67.4 \%$ seguidos de de BH fueron la S-EC con $89.6 \%$ y la Cayo Blanco (Cy.Bl) (27.6\%) y sur de SE-Cy.DP2 con 16.2\% (Fig. 4B).

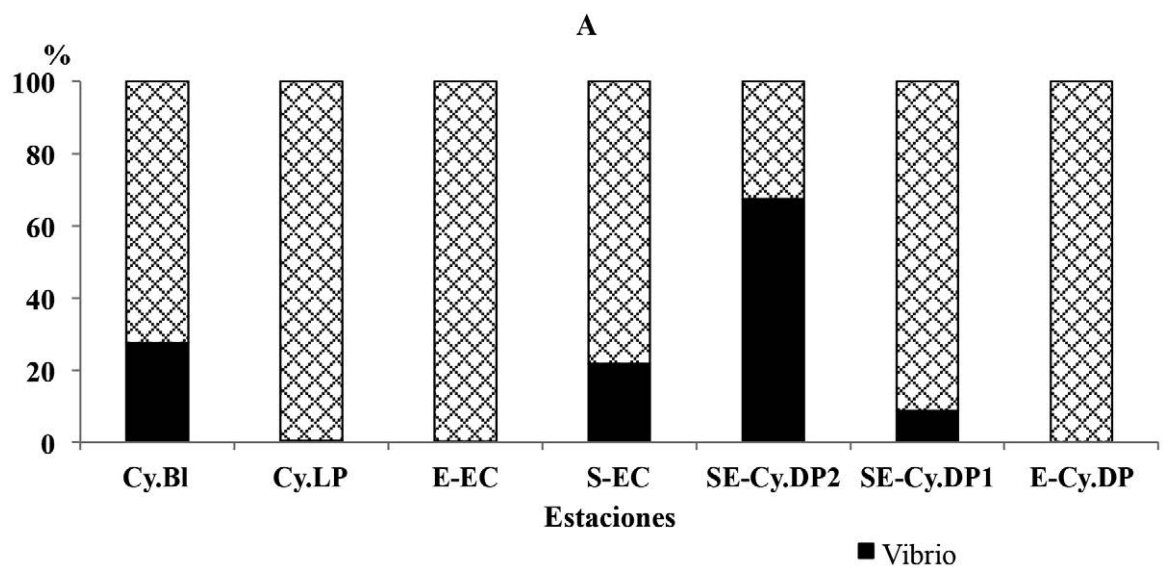

B

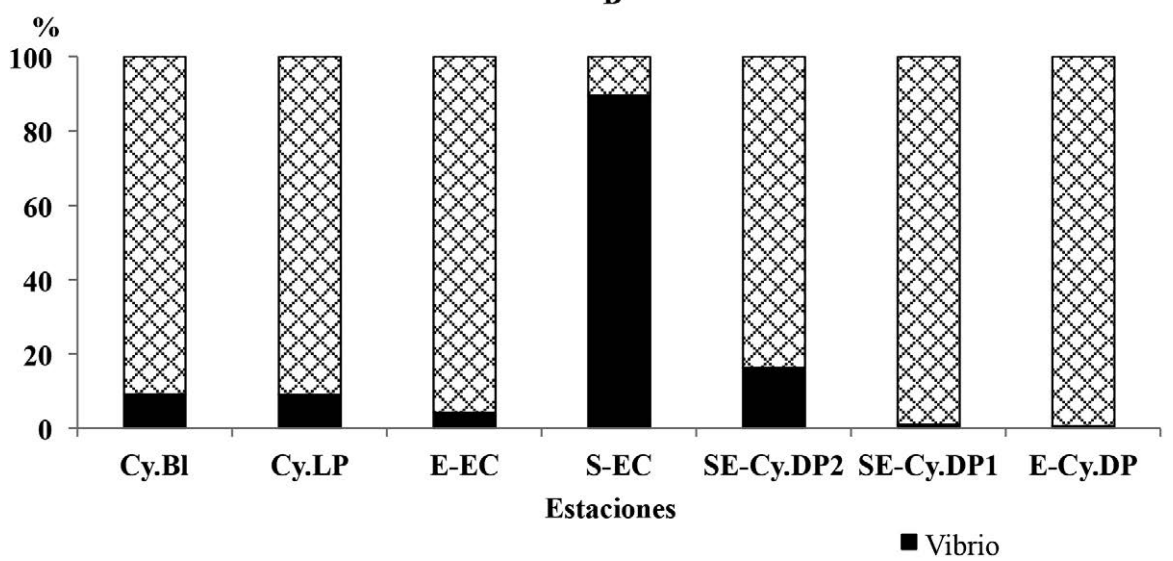

Fig. 4. Contribución relativa de la concentración de vibrios al total de bacterias heterótrofas en los arrecifes frontales del golfo de Cazones. A: noviembre 2015, B: abril 2017

Fig. 4. Relative contribution of vibrio to the total heterotrophic bacteria concentration on the frontal reefs in the Gulf of Cazones. A: November 2015, B: April 2017 
En todos los sitios de crestas arrecifales se obtuvo crecimiento de bacterias sulfatorreductoras en los micronicronichos muestreados, en las dos épocas. En el análisis por muestreo se encontró que en noviembre 2015, las concentraciones de BSR fueron elevadas variando entre 210$2400 \mathrm{NMP} / 100 \mathrm{~mL}^{-1}$. Sin embargo, en abril 2017 las concentraciones fueron relativamente bajas $(0.2$ y $75 \mathrm{NM}$ $\mathrm{P} / 100 \mathrm{~mL}^{-1}$ ) (Cuadro 2). Las estaciones donde se encontraron las mayores concentraciones de BSR fueron cayo Sigua (Cy.Si) (2 $400 \mathrm{NMP} / \mathrm{mL})$ y sureste de cayo Diego Pérez 1 (SE-Cy.DP1) (2 $400 \mathrm{NMP} / \mathrm{mL}$ ) seguida de sureste de cayo Diego Pérez 2 (SE-Cy.DP2) (1 $100 \mathrm{NMP} / \mathrm{mL}$ ), en el mes de noviembre 2015 (Cuadro 2).

Este resultado indica la presencia de micronichos con condiciones de anaerobiosis, ya que las BSR se desarrollan en ausencia de oxígeno y, aunque son bajas las concentraciones encontradas, debe servir de alerta para el buen estado de salud de esos arrecifes. Sin embargo, todos los sitios de los arrecifes frontales presentaron valores adecuados de BSR. En los arrecifes frontales no se detectaron BSR en ninguno de los dos muestreos realizados (Cuadro 2).

Cuadro 2. Concentración de bacterias sulfatorreductoras (BSR) en los micronichos de los arrecifes del golfo de Cazones (noviembre 2015 y abril 2017) Table 2. Concentration of sulphate-reducing bacteria in the micro niches on the Gulf of Cazones reefs (November 2015 and April 2017)

\begin{tabular}{lcc}
\hline \multicolumn{1}{c}{ Ubicación de los sitios } & $\begin{array}{c}\text { Concentración de BSR (NMP/100 mL) } \\
\text { noviembre 2015 }\end{array}$ & $\begin{array}{c}\text { abril 2017 } \\
\text { Crestas arrecifales }\end{array}$ \\
\hline Vizcaínos (Vi) & 750 & $<0.3$ \\
Cayo Sigua (Cy.Si) & 2400 & 39 \\
Sur de la ensenada de Cazones (Nirvana) (S-EC) & 210 & 75 \\
Sureste de cayo Diego Pérez 2 (SE-Cy.DP2) & 1100 & 30 \\
Sureste de cayo Diego Pérez 1 (SE-Cy.DP1) & 2400 & 11 \\
& \multicolumn{1}{c}{ Arrecifes frontales } \\
Cayo Blanco (Cy.Bl) & $<0.2$ & $<0.2$ \\
Cayo Los Pinos (Cy.LP) & $<0.2$ & $<0.2$ \\
Este de la ensenada de Cazones (E-EC) & $<0.2$ & $<0.2$ \\
Sur de la ensenada de Cazones (S-EC) & $<0.2$ & $<0.2$ \\
Sureste de cayo Diego Pérez 2 (SE-Cy.DP2) & $<0.2$ & $<0.2$ \\
Sureste de cayo Diego Pérez 1 (SE-Cy.DP1) & $<0.2$ & $<0.2$ \\
Oeste de la ensenada de Cazones (O-EC) & $<0.2$ & $<0.2$ \\
Este de cayo Diego Pérez (E-Cy.DP) & $<0.2$ & \\
\hline
\end{tabular}


Al analizar el estado trófico de frontales el 63\%. En abril del 2017, las aguas a partir de la concentración de bacterias heterótrofas, en ambos muestreos se encontró que la clasificación varió entre mesotrófica a meso-eutrófica (Cuadro 3). Es importante señalar que en los sitios evaluados de las crestas arrecifales en el golfo de Cazones en noviembre del 2015, el $80 \%$ de las estaciones se clasificaron como mesotróficas, y en los arrecifes todos los sitios de las crestas se calificaron como mesotróficos y en los arrecifes frontales solo el $25 \%$ como meso-eutrófico (Cuadro 3). Los resultados anteriores sugieren que las aguas aledañas a los arrecifes del golfo de Cazones se mantienen enriquecidas de materia orgánica, tanto en las crestas como en los arrecifes frontales.

Cuadro 3. Estado trófico de las aguas de los arrecifes del golfo de Cazones a partir de la clasificación basada en la concentración de bacterias heterótrofas (Miravet et al. 2009)

Table 3. Trophic state of the waters of the Gulf of Cazones reefs based on the heterotrophic bacteria concentration classification (Miravet et al. 2009)

\section{Ubicación de los sitios}

Clasificación del estado trófico noviembre 2015

Crestas arrecifales

Vizcaínos (Vi)
Cayo Sigua (Cy.Si)
Sur de la ensenada de Cazones (S-EC)
Sureste de cayo Diego Pérez 2 (SE-Cy.DP2)
Sureste de cayo Diego Pérez 1 (SE-Cy.DP1)
Cayo Blanco (Cy.Bl)
Cayo Los Pinos (Cy.LP)
Este de la ensenada de Cazones (E-EC)
Sur de la ensenada de Cazones (S-EC)
Sureste de cayo Diego Pérez 2 (SE-Cy.DP2)
Sureste de cayo Diego Pérez 1 (SE-Cy.DP1)
Oeste de la ensenada de Cazones (O-EC)
Este de cayo Diego Pérez (E-Cy.DP)

\begin{tabular}{|l|}
\hline Clasificación \\
\hline Mesotróficas \\
\hline Meso-eutróficas \\
\hline Eutróficas \\
\hline
\end{tabular}

$\begin{array}{ll}1133 & 4454 \\ 3800 & 3242 \\ 7233 & 3375 \\ 4633 & 3242 \\ 4133 & 4939\end{array}$

Arrecifes frontales

\begin{tabular}{|rr}
3087 & 3364 \\
2133 & 3000 \\
8467 & 4159 \\
7300 & 1364 \\
2300 & 4318 \\
4050 & 14788 \\
20435 & 21879 \\
\hline 3087 & 3364 \\
\hline
\end{tabular}

$\mathrm{UFC} / \mathbf{m L}$

$80.1-6500.0$

$6500.1-27000.0$

$27000.1-120000.0$ 


\section{DISCUSIÓN}

En los arrecifes de coralinos, las comunidades microbianas desempeñan un papel importante en la remineralización de los componentes orgánicos a inorgánicos, así como en la transferencia de energía a otros niveles tróficos (Henschke et al. 2016; Kirchman, 2000; Pucci et al. 2009). De hecho, algunos estudios informan que los microorganismos heterótrofos reciclan más de la mitad de la productividad neta en estos ecosistemas (Cho \& Azam, 1990; Motegi et al. 2013; Nelson et al. 2011).

Según van Duyl \& Gast (2001), aunque existe escasa información sobre el proceso de mineralización en el ecosistema arrecifal, se reconoce que la descomposición de la materia orgánica en los arrecifes ocurre con rapidez, ya que el flujo neto de materia orgánica en este ecosistema es generalmente pequeño.

La abundancia de bacterias que rodean los arrecifes está fuertemente influenciada por el movimiento de las aguas, el tiempo de residencia de estas sobre las crestas, el grado de depredación que sufren las bacterias, lo que a su vez se relaciona con la presencia y abundancia de otros organismos y la producción de mucus y materia orgánica que tiene lugar por los corales y los organismos que viven asociados a estos (Gast, 1998). Esto significa que la aparición de gradientes de concentración de bacterias en diferentes sitios del arrecife puede depender, en gran medida, del grado de cobertura que presente el ecosistema en el momento del muestreo y, además, de la entrada de materia orgánica de origen antrópico que pueda ocurrir de manera eventual por diferentes causas.

En general, las concentraciones de $\mathrm{BH}$ encontradas, tanto en las crestas como en los arrecifes profundos del golfo de Cazones, en el muestreo de abril del 2017, resultaron inferiores a las informadas para la misma zona en noviembre del 2015. No obstante, los resultados de abril 2017 confirman la disponibilidad de materia orgánica en las aguas aledañas, ya que estas bacterias, para su crecimiento y duplicación necesitan la materia orgánica. De hecho, las altas concentraciones de demanda química de oxígeno (DQO) detectadas en el golfo de Cazones pudieran estar asociadas a materia orgánica que proviene del aporte de la plataforma del golfo de Batabanó y por el escurrimiento superficial y subterráneo de la ciénaga de Zapata (Lluis-Riera, 1983; Petrova et al. 2007), además del sistema de corrientes que entrampa la materia orgánica y a los microorganismos (Arriaza et al. 2012; Lugioyo, 2003) y, a partir del metabolismo autotrófico y por la muerte de los organismos de estos ecosistemas arrecifales. También se debe tener en cuenta el aporte de materia orgánica procedente de los tapetes 
de cianobacterias que se encontraron en los arrecifes coralinos del golfo de Cazones. Brocke et al. (2015) cuantificaron los aportes de carbono orgánico disuelto (COD) por las cianobacterias para arrecifes coralinos del Caribe e informaron que estas liberan entre 0.4 y $1 \mathrm{mg} \mathrm{C} / \mathrm{m}^{2} / \mathrm{d}$.

En general, los arrecifes del golfo de Cazones presentaron concentraciones de materia orgánica (DQO) superiores a la unidad y en algunos sitios los valores alcanzaron cifras entre 2.24 y $6.72 \mathrm{mg} / \mathrm{L}$, que llegaron hasta los $10.88 \mathrm{mg} / \mathrm{L}$ (Loza et al. 2017). Estas elevadas concentraciones de materia orgánica contribuyeron al elevado estado trófico de las aguas que los rodean, cuyas características van desde mesotróficas hasta meso-eutróficas. Los máximos puntuales de DQO obtenidos en los arrecifes del golfo de Cazones superaron los valores informados para los arrecifes del golfo de Batabanó por Miravet (2003) y en el archipiélago Sabana-Camagüey (ASC) por Montalvo et al. (2013).

Los resultados obtenidos en los arrecifes del golfo de Cazones confirman lo referido por Williams (2000), quien planeó que la mayor o menor abundancia de bacterias heterótrofas constituye un indicador de la cantidad de materia orgánica presente, relación que establece un nexo entre la cantidad de materia orgánica disuelta lábil capaz de ser oxidada por la actividad bacteriana.
Se ha demostrado que los arrecifes prístinos tienen una comunidad microbiana asociada que refleja e indica que un arrecife de coral está saludable; sin embargo, a medida que las actividades antrópicas alrededor de este ecosistema se vuelven más intensas, las bacterias patógenas tienden a proliferar. Entre ellas se encuentran los vibrios, en gran medida los responsables de enfermedades.

Uno de los grupos de bacterias que se encuentran ampliamente distribuidos en los ecosistemas marinos son los vibrios y, en particular, en los arrecifes coralinos son considerados indicadores importantes para evaluar el "estado de salud", ya que están asociados a una amplia gama de enfermedades de corales (Ben-Haim \& Rosenberg, 2002; Kushmaro et al. 2001; Sweet \& Bulling, 2017). En este sentido, las elevadas concentraciones de vibrio detectadas en algunos sitios de los arrecifes del golfo de Cazones como Cy-Si, SE-Cy.DP2 y al sur de la ensenada de Cazones (S-EC, indican, desde el punto de vista microbiológico, que son más vulnerables al deterioro de su estado de salud.

La contribución relativa de los vibrios al total de las bacterias heterótrofas aerobias en las aguas aledañas de las crestas y arrecifes frontales del golfo de Cazones evidenció que, en algunas estaciones como la del sur de la ensenada de Cazones en la cresta (S-EC) y SE-Cy.DP2, en el arrecife 
profundo, los porcentajes de vibrio fueron muy elevados, lo que indica la importancia de este grupo dentro de las bacterias heterótrofas totales en dichas zonas. Destaca que, coincidentemente en la estación S-EC, se observaron las mayores concentraciones de bacterias heterótrofas aerobias, todo lo cual debe servir de alerta, pues el estado de salud de ese arrecife tiene condiciones, desde el punto de vista microbiológico, para el deterioro de este sitio.

Sin embargo, Loza et al. (2017) informan que la tendencia en los arrecifes del golfo de Cazones (tanto en crestas como arrecifes frontales) entre el 2001 y el 2017 fue mantener bajos porcentajes de enfermedades y a ir disminuyendo en el tiempo. Según Yakob \& Mumby (2011), la incidencia de enfermedades está disminuyendo debido a que las comunidades de corales están siendo más resistentes a los patógenos y a la colonización de epizoos.

Otro indicador microbiano que debe tenerse en cuenta en la evaluación del estado de salud de los arrecifes son las bacterias sulfatorreductoras. En el desarrollo de esta investigación se encontraron elevadas concentraciones de bacterias sulfatorreductoras en micronichos de las estaciones de crestas arrecifales, lo que indica una acumulación de materia orgánica y, por tanto, un consumo del oxígeno provocado por la descomposición de esa materia orgánica (Gast et al. 1999), todo lo cual posibilita el deterioro de la calidad de ese ecosistema, ya que las BSR solo se desarrollan en ambientes anóxicos o reducidos y, por tanto, pudiera ser una señal de empeoramiento de la salud de esos arrecifes.

Al comparar los resultados obtenidos de las BSR en el golfo de Cazones con los informados por Miravet (2003) para los arrecifes que bordean el golfo de Batabanó, ubicados en la zona SW, entre 1998 y 1999, los valores detectados de BSR en las crestas arrecifales del golfo de Cazones fueron superiores hasta en dos órdenes y similares a los informados por Miravet et al. (1994) en una investigación realizada en las aguas de los arrecifes que bordean el archipiélago Sabana-Camagüey.

Las relaciones obtenidas entre los factores bióticos y abióticos en las aguas de los ecosistemas arrecifales del golfo de Cazones sugieren que los microorganismos desempeñan un papel fundamental en el funcionamiento de la trama trófica en los ecosistemas marinos y ponen de manifiesto los procesos fundamentales que ocurren en los ecosistemas arrecifales, como son la remineralización, donde las bacterias heterótrofas aerobias descomponen la materia orgánica, y aportan nutrientes, fundamentalmente, las formas oxidadas del nitrógeno (NOx). 


\section{CONCLUSIONES}

Los arrecifes más vulnerables al deterioro ambiental, tomando en consideración los indicadores microbiológicos de calidad de las aguas en el golfo de Cazones, son SE-Cy.DP2, SE-Cy. DP1 y S-EC, pues presentan elevadas concentraciones de materia orgánica (DQO), de bacterias heterótrofas, de sulfatorreductoras y de vibrios.

Las aguas en los arrecifes del golfo de Cazones, en general, se clasifican de mesotróficas a meso-eutróficas, de acuerdo con los indicadores microbiológicos, lo que refleja condiciones de nutrificación debido al deterioro de sus condiciones ambientales.

\section{AGRADECIMIENTOS}

Esta investigación ha sido posible por el financiamiento de la Comisión Europea al proyecto "Evaluación de los Impactos Potenciales del Cambio Climático sobre la Biodiversidad y Desarrollo de Estrategias de Adaptación en dos Regiones de Ecosistemas Frágiles de Cuba". Se agradece a la Fundación Antonio Núñez Jiménez de la Naturaleza y el Hombre por ser la responsable de la logística de las expediciones marinas.

\section{BIBLIOGRAFÍA}

Alcolado, P. M., Morgan, I. E., Kramer, P. A., Ginsburg, R. N., Blanchon, P., de la Guardia, E., Kosminin, V., González-Ferrer, S. \& Hernández, M. (2010). Condition of remote reefs of southwest Cuba. Cienc. Mar, 36(2), 179-197.

Anderson, M. J. \& Millar, R. B. (2004). Spatial variation and effects of habitat on temperate reef fish assemblages in northeastern New Zealand. J. Exp. Mar Biol. Ecol., 305(2), 191-221. https:// doi.org/10.1016/j.jembe.2003.12.011.

Anderson, M. J., Gorley, R. N. \& Clarke, K. R. (2008). PERMANOVA for PRIMER: Guide to Software and Statistical Methods. UK, PRIMER-E Ltd.

APHA. (2012). Standard methods for the examination of water and wastewater (22nd ed.). EE. UU. American Water Works Association (AWWA).

Arriaza, L., Hernández, M., Lorenzo, S., Olivera, J., Rodas, L., Montesino, D. \& Navarro-Padrón, J. (2012). Modelación numérica de corrientes marinas alrededor del occidente de Cuba. Ser. Oceanol., 10, 11-22.

Aronson, R. B. \& Precht, W. F. (2001). White-band disease and the changing face of Caribbean coral reefs. Hydrobiol., 460, 25-38. https://doi. org/10.1007/978-94-017-3284-0_2

Ben-Haim, Y. \& Rosenberg, E. (2002). A novel Vibrio sp. pathogen of the coral Pocillopora damicornis. Mar. Biol., 144, 47-55. https://doi.org/10.1007/ s00227-002-0797-6.

Brocke, H, J., Wenzhoefer, F., De Beer, D. Mueller, B., Van Duyl, F. C. \& Nugues, M. M. (2015). High dissolved organic carbon release by benthic cyanobacterial mats in a Caribbean reef ecosystem. Sci. Rep. 5, 8852 . 
Cho, B. C. \& Azam, F. (1990). Biogeochemical significance of bacterial biomass in the ocean's euphotic zone. Mar. Ecol. Prog. Ser., 63, 253-259.

Eakin, C. M., Morgan, J. A., Heron, S. F., Smith, T. B., Liu, G. \& Alvarez-Filip, L. (2010). Caribbean corals in crisis: Record thermal stress, bleaching, and mortality in 2005. PLOS ONE 5(11), e13969.

Gardner, T. A., Cote, I. M., Gill, J. A., Grant, A. \& Watkinson, A. R. (2003). LongTerm Region-Wide Declines. Caribb. Corals. Sci., 301, 958-960.1126/ science. 1086050

Gast, G. J. (1998). Microbial Densities and Dynamics in Fringing Coral Reef Waters (Tesis de Doctorado no publicada). University of Amsterdam, The Netherlands.

Gast, G. J., Jonkers, P. Y., van Duyl, F. \& Bak, R. (1999). Bacteria, flagellates and nutrients in island fringing coral reef waters: influence of the ocean, the reef and eutrophication. Bull. Mar. Sci., 65(2), 523-538.

Ginsburg, R. N. \& Glynn, P. W. (1994). Summary of the colloquium and forum on global aspects of coral reefs. In R. N. Ginsburg (Ed.), Proceedings of the Colloquium on Global Aspects of Coral Reefs: Health, Hazards and History (pp. 1-8). EE. UU.: Rosenstiel School of Marine and Atmospheric Science, University of Miami.

Harvey, B. J., Nash, K. L., Blanchard, J. L. \& Edwards, D. P. (2018). Ecosystem-based management of coral reefs under climate change. Ecol. Evol., 8, 6354-6368. https://doi.org/10.1002/ ece3.4146.

Henschke, N., Everett, J. D., Richardson, A. J. \& Suthers, I. M. (2016). Rethinking the role of salps in the ocean. Trends
Ecol. Evol., 31(9), 720-33. https://doi. org/10.1016/j.tree. 2016.06.007.

Hoegh-Guldberg, O, Mumby, P. J., Hooten, A. J., Steneck, R. S., Greenfield, P., Gomez, E. .... \& Hatziolos, M. E. (2007). Coral Reefs Under Rapid Climate Change and Ocean Acidification. Review. Science, 318, 1737-1742. https:// doi.org/10.1126/science.1152509

Hughes, T. P, Graham, N. A. J., Jackson, J. B. C., Mumby, P. J. \& Steneck, R. S. (2010). Rising to the challenge of sustaining coral reef resilience. Trends Ecol. Evol., 25, 633-642. https://doi. org/10.1016/j.tree.2010.07.011.

Hughes, T. P., Anderson, K. D., Connolly, S. R., Heron, S. F., Kerry, J. T., Lough, J. M., ... \& Wilson, S. K. (2018). Spatial and temporal patterns of mass bleaching of corals in the Anthropocene. Science, 359, 80.

Jackson, J. B. C., Donovan, M. K., Cramer, K. L. \& Lam, V. V. (2014). Status and Trends of Caribbean Coral Reefs: 1970-2012. Switzerland: Global Coral Reef Monitoring Network, IUCN.

Jiang, S. C. (2001). Vibrio cholerae in recreational beach water sand tributaries of Southern California. Hydrobiol., 460, 157-164.

Kushmaro, A., Banin, E., Loya, Y., Stackebrandt, E. \& Rosenberg, E. (2001). Vibrio shiloi sp. nov., the causative agent of bleaching of the coral Oculina patagonica. Int. J. Syst. Evol. Microbiol., 51, 1383-1388. https://doi. org/10.1099/00207713-51-4-1383.

Kirchman, D. L. (2000). Uptake and Regeneration of Inorganic Nutrients by Marine Heterotrophic Bacteria. In D. L. Kirchman (Ed.), Microbial Ecology of the Oceans (pp. 262-288). EE. UU.: Wiley-Liss.

Kleypas, J. \& Hoegh-Guldberg, O. (2008). Coral reefs and climate change: 
susceptibility and consequences. In C. Wilkinson \& D. Souter (eds.), Status of Caribbean Coral Reefs after Bleaching and Hurricanes in 2005 (pp. 19-29). Australia.: Global Coral Reef Monitoring Network and Rainforest Research Center.

Loza, S., Busutil, L., Rodríguez, S., Lugioyo, G. M., García, I., Rey-Villier, N.,....\& Hernández-Zanuy, A. (2017). Evaluación de la vulnerabilidad de la biodiversidad marino-costera al cambio climático en los arrecifes coralinos del golfo de Cazones y del archipiélago Jardines de la Reina. Cuba: ICiMAR.

Lluis-Riera, M. (1983). Régimen hidrológico de la plataforma insular de Cuba. Cien. Tierr. Esp., 7, 81-110.

Lugioyo, G. M. (2003). Distribución, relaciones tróficas y diversidad del bacterioplancton de las aguas oceánicas de Cuba (Tesis de doctorado no publicada). Universidad de La Habana, Cuba.

Miravet, M. E. (2003). Abundancia, actividad $y$ diversidad de las bacterias heterótrofas en el Golfo de Batabanó y su uso como indicadoras ambientales. (Tesis de doctorado no publicada). Universidad de La Habana, Cuba.

Miravet, M. E., Martínez-Daranas, B. \& Penie, I. (1994). Indicadores microbiológicos del estado de salud de los arrecifes que bordean el archipiélago Sabana-Camagüey. Cuba: Instituto de Oceanología.

Miravet, M. E., Lugioyo, M., Loza, S., Enríquez, D., Delgado, Y., Carmenate, M. \& Pérez, D. (2009). Procedimientos para el monitoreo de la calidad ambiental en la zona marino costera a partir de microorganismos. República Dominicana: Centenario.

Montalvo-Estévez, J. F., García-Ramil, I., Perigó-Arnaud, E., Alburquerque-Brook, O.C. \& García-García, N. (2013).
Calidad química del agua y sedimento en las bahías del archipiélago Sabana-Camagüey. Rev. Cub. Quim., 25(2), 123-133.

Motegi, C., Tanaka, T., Piontek, J., Brussaard, C. P. D., Gattuso, J. P. \& Weinbauer, M. G. (2013). Effect of $\mathrm{CO}_{2}$ enrichment on bacterial metabolism in an Arctic fjord. Biogeosciences, 10, 3285-3296.

Nelson, C., Alldredge A. L., McCliment, E. A, Amaral-Zettler, L. A. \& Carlson, C. A. (2011). Depleted dissolved organic carbon and distinct bacterial communities in the water column of a rapid-flushing coral reef ecosystem. Int. Soc. Microb. Ecol. J., 5, 1374-1387. https://doi. org/10.1038/ismej.2011.12.

Pandolfi, J. M., Jackson, J. B. C., Baron, N., Bradbury, R. H., Guzman, H. M., Hughes, T. P. \& Sala, E. (2005). Are US coral reefs on the slippery slope to slime? Science, 307, 1725-1726. https:// doi.org/10.1126/science.1104258.

Petrova, V., Villasuso, M. \& Alfonso, A. (2007). Manejo de los recursos hidricos en los humedales. Caso de estudio Ciénaga de Zapata (Parte IV). República Dominicana: Centenario.

Pucci, G. N., Acuña, A. J. Llanes, M. L., Tiedemann, M. C. \& Pucci, O. H. (2009). Identificación de bacterias marinas cultivables de la ciudad costera Comodoro Rivadavia, Argentina. Rev. Biol. Mar. Oceanogr., 44, 49-58. http://dx.doi.org/10.4067/ S0718-19572009000100005.

Rey-Villiers, N. (2016). Breve descripción oceanográfica de los golfos Batabanó, Ana María y Guacanayabo. En N. Rey-Villiers (Ed.), Linea base ambiental para el estudio del cambio climático en el golfo de Cazones y el archipiélago Jardines de la Reina, Cuba (pp.16-19). Cuba: Instituto de Oceanología, CITMA. 
Spalding, M., Burke, M., Wood, S. A., Ashpole, J., Hutchison, J. \& Ermgassen, P. (2017). Mapping the global value and distribution of coral reef tourism. Mar. Pol., 82, 104-113. http://dx.doi. org/10.1016/j.marpol.2017.05.014

Sweet, M. J. \& Bulling, M. T. (2017). On the Importance of the Microbiome and $\mathrm{Pa}$ thobiome in Coral Health and Disease. Front. Mar. Sci., 4(9), 1-11. https://doi. org/10.3389/fmars.2017.00009.

Thampi, V. A., Madhur, A. \& Chris, T. B. (2018). Socio-ecological dynamics of Caribbean coral reef ecosystems and conservation opinion propagation. Scien. Rep. 8, 2597. https://doi. org/10.1038/s41598-018-20341-0.

Thompson J. R. \& Polz M. F. (2006). Dynamics of Vibrio populations and their role in environmental nutrient cycling. In F. Thompson, B. Austin \& J. Swings (Eds), The Biology of Vibrios (pp. 190203). EE. UU.: ASM Press.

van Duyl, C. \& Gast, G. J. (2001). Linkage of small-scale spatial variations in DOC, inorganic nutrients and bacterioplankton growth with different coral reef water types. Aquat. Microb. Ecol., 24, $17-26$.
Weijerman, M., Veazey, L., Yee, S., Vaché, K., Delevaux, J. M. S., Donovan, M. K. \& ... Oleson, K. L. L. (2018). Managing Local Stressors for Coral Reef Condition and Ecosystem Services Delivery Under Climate Scenarios. Front. Mar. Sci., 5, 425. https://doi.org/10.3389/ fmars.2018.00425.

Williams, P. J. (2000). Heterotrophic Bacteria and the Dynamics of Dissolved Organic Material. In D. L. Kirchman (Ed.), Microbial Ecology of the Oceans (pp. 153-200). EE. UU.: Wiley-Liss.

Williams, G. J., Graham, N. A. J., Jouffray, J. B., Norström, A. V., Nyström, M., Gove, J. M., A. Heenan, A. \& Wedding, L. M. (2019). Coral reef ecology in the Anthropocene. Functional Ecol., 33, 1014-1022. https://doi. org/10.1111/1365-2435.13290

Yakob, L. \& Mumby, P. (2011). Climate change induces demographic resistance to disease in novel coral assemblages. Proc. Nat. Acad. Sci., 108(5), 1967-1969. https://doi.org/10.1073/ pnas. 1015443108 . 